lần lượt là 0,$512 ; 0,658 ; 0,409(p<0,01)$. Chỉ số Tei thất phải lại cho thấy mối tương quan nghịch biến với thông số này $(r=-0,372 p<0,05)$.

Nghiên cứu của Nguyễn Phương Trang trên nhóm bệnh nhân suy tim chức năng thất trái $\mathrm{EF}$ $<40 \%$ cũng cho thây mối tương quan mạnh giữa các chỉ số Tapse, FAC, $\mathrm{S}$ với thống số $\mathrm{EF}$ $(r=0,632 ; 0,710 ; 0,582 ; p<0,001) 5$. Điều này cũng tương tự như trong nghiên cứu của Nguyễn Bá Tâm trong nhóm bệnh nhân sau nhồi máu cơ tim thành trước cũng cho thấy mối liên quan giữa chỉ số Tapse và $E F(r=0,33, p<0,05) 6$. Nghiên cứu của Sarinya Puwanant và cộng sự năm 2009 đánh giá chức năng thất phải ở các bệnh nhân suy tim chức năng thất trái giảm và bảo tồn cũng cho thấy chỉ số Tapse, $\mathrm{FAC}, \mathrm{S}^{\prime}$ có tương quan tốt với chỉ số $E F$. FAC $(R=0,46 p<0,01)$ Tapse $(r=0,48 ; P<0,01) S^{\prime}(r=0,48 ; p=0,01) 7$

\section{KẾT LUÂN}

Suy chức năng thất phải khá thường gặp ở BN hẹp chủ khít. Chức năng thất phải có tương quan với vận tốc tối đa qua van động mạch chủ (TAPSE), với chỉ số diện tích van đông mạch chủ (FAC, S', Tei mô) và chức năng tâm thu thất trái.

\section{TÀI LIÊU THAM KHẢO}

1. Ren B, Spitzer E, Geleijnse ML, et al. Right ventricular systolic function in patients undergoing transcatheter aortic valve implantation: A systematic review and meta-analysis. Int J Cardiol. 2018;257:40-45. doi:10.1016/j.ijcard.2018.01.117

2. Right heart dysfunction in heart failure with preserved ejection fraction | European Heart Journal | Oxford Academic. Accessed August 11, 2021. https://academic.oup.com/ eurheartj/article/ $35 / 48 / 3452 / 472871$ ?login=true

3. Santamore WP, Dell'Italia LJ. Ventricular interdependence: Significant left ventricular contributions to right ventricular systolic function. Progress in Cardiovascular Diseases. 1998;40 (4):289-308. doi:10.1016/S0033-0620(98)80049-2

4. Galli $E$, Guirette $Y$, Feneon $D$, et al. Prevalence and prognostic value of right ventricular dysfunction in severe aortic stenosis. Eur Heart J Cardiovasc Imaging. 2015;16(5):531-538. doi:10,1093/ehjci/jeu290

5. Nguyễn Thu Trang NTBY. Khảo sát chức năng thất phải bằng siêu âm tim ở bệnh nhân suy tim có $\mathrm{EF}<40 \%$ so với nhóm suy tim EF $>40 \%$. Published online 2020. http://thuvien.hmu.edu.vn/ pages/cms/FullBookReader.aspx

6. Nguyễn Tá Tâm NTBY. Bước đâu đánh giá chưc năng thất phải bằng chỉ số Tapse trên siêu âm tim ở bệnh nhân nhồi máu cơ tim ST chênh lên sau can thiêp. Published online 2017. http://t huvien.hmu.edu.vn/pages/cms/FullBookReader.aspx

7. Puwanant S, Priester TC, Mookadam F, Bruce CJ, Redfield MM, Chandrasekaran K. Right ventricular function in patients with preserved and reduced ejection fraction heart failure. European Journal of Echocardiography. 2009;10(6):733-737. doi:10.1093/ejechocard/jep052

\title{
TẦN SUẤT SỬ DƯNG THỨC ĂN NHANH VÀ CÁC YẾU TỐ LIÊN QUAN CỦA HỌC SINH TRƯờnG TRUNG HỌC PHỔ THÔNG HÙNG VƯƠNG, THÀNH PHỐ HỒ CHÍ MINH
}

\author{
Trần Quốc Huy*, Nguyễn Ngọc Bích*, Đoàn Duy Tân*
}

\section{TÓM TẮT}

Đặt vấn đề: Thức ăn nhanh ngày nay phổ biến ở khắp nỡi trên thế giới và được người dân yêu thích sử dụng, trong đó có Viêtt Nam. Sử dụng thức ăn nhanh thường xuyên mất kiểm soát làm tăng nguy cơ mắc một số bệnh lý như thừa cân, béo phì, tăng huyết áp và các bệnh lý về đường tiêu hóa. Mục tiêu: Xác định tần suất sử dụng thức ăn nhanh vă các yếu tố liên quan của học sinh trường Trung hoc phổ thông (THPT) Hùng Vương năm 2021. Đối tượng và phương pháp nghiên cứu: Nghiên cứu mồ tả cắt ngang thực hiện trên 420 học sinh trường THPT Hùng

*Đại học Y Dược Thành phố Hồ Chí Minh

Chịu trách nhiệm chính: Đoàn Duy Tân

Email: doanduytaan@ump.edu.vn

Ngày nhận bài: 20.9.2021

Ngày phản biện khoa học: 2.11.2021

Ngày duyệt bài: 22.11.2021
Vương, quận 5, thành phố Hồ Chí Minh(TP.HCM) năm 2021. Kết quả: Tần suất sử dung thức ăn nhanh 1-3 lần/tháng của học sinh chiếm tỉ lệ cao nhất 43,3\%. Tỉ lê thừa cân ở hoc sinh THPT chiếm $15,7 \%$, tỉ lệ béo phì chiếm $4,3 \%$. Gà rán và khoai tây chiên là hai loai thức ăn nhanh sử dung phổ biến nhất với tỉ lệ lần lượt là $81,1 \%$ và $69,2 \%$. Thương hiệu thức ăn nhanh được sứ dụng nhiêuu nhất là KFC với $70,6 \%$. Lý do sử dụng thức ăn nhanh phổ biến nhất là hương vị chiếm $85 \%$. Nghiên cứu tìm thấy mối liên quan giữa tần suất sử dụng thức ăn nhanh với tần suất sử dụng bữa cơm gia đình $(p<0,001)$ và yếu tố $c h a / m e$ sử dụng thức ăn nhanh thường xuyên $(p<0,05)$. Kết luận: Để giảm tần suất sử dụng thức ăn nhanh của con cái, gia đình nên chủ động chuẩn bị và sử dụng bữa cớm gia đình cùng nhau, đồng thời phụ huynh nên han chế sử dụng thức ăn nhanh. béo phì.

Tư khóa: Thức ăn nhanh, dinh dưỡng, thừa cân 


\section{SUMMARY}

\section{FREQUENCY OF FAST FOOD CONSUMPTION AND RELATED FACTORS OF STUDENTS OF HUNG VUONG HIGH SCHOOL, HO CHI MINH CITY}

Background: Fast food has become more and more popular all over the world and is preferred by many people among whom Vietnamese people contribute a considerable proportion. The consumption of fast food without restriction increases the risk of some diseases like overweight, obesity, hypertension and gastrointestinal problems. Objectives: To determine the frequency of fast food consumption and other related factors of students of Hung Vuong high school in the year 2021.Materials and methods: Cross sectional descriptive study conducted on 420 students of Hung Vuong high school, district 5, Ho Chi Minh city, in the year 2021. Results: The frequency of fast food consumption of 1-3 times per month accounted for the highest percentage $(43.3 \%)$. The proportion of overweight students accounted for $15.7 \%$, and the figure for obese ones constituted $4.3 \%$. Fried chicken and french fries were the 2 kinds of food that were most commonly consumed with the rates of $81.1 \%$ and $69.2 \%$ respectively. The most commonly visited fast food chain was KFC with $70.6 \%$. The most popular reason for consuming fast food was the taste and flavor (accounting for $85 \%$ ). The study found the connection between the frequency of fast food consumption and that of eating homemade food $(p<0.001)$ and the factor of parents' consuming fast food frequently $(p<0.05)$. Conclusions: In order to reduce the frequency of fast food consumption of children, families should be proactive in preparing and eating homemade food together, and parents should also decrease their own consumption of fast food.

Keywords: Fast food, nutrition, overweight, obesity

\section{I. ĐĂT VẤN ĐỀ}

Thức ăn nhanh rất tiện lợi và nhanh chóng nên được người dân yều thích sử dụng, tuy nhiên việc sử dụng thức ăn nhanh thường xuyên mất kiểm soát sẽ dẫn đến rất nhiều vấn đề sức khỏe. Thức ăn nhanh chứa nhiều chất béo không tốt, nhiều năng lượng, nhiều muối nhưng lại rất ít và hầu như không chứa chất xớ [3], sử dụng thức ăn nhanh thường xuyên làm tăng nguy cơ mắc thừa cân, béo phì từ $1,29-3,88$ lần so với việc không tiêu thụ thức ăn nhanh [4], [7]. Những bệnh lý này sẽ gây ra những ảnh hưởng trực tiếp đến kết quả hoọc tập, sức khỏe thể chất, tinh thần và cả sức khỏe sinh sản của học sinh, đặc biệt là lứa tuổi học sinh THPT. Trường THPT Hùng Vương nằm ở địa điểm nội thành của TP.HCM nơi có hê thống cửa hàng thức ăn nhanh đông đúc, đa dạng dễ dàng có sự tiếp cận của học sinh, tuy nhiển lại chưa có nghiên cứu tìm hiểu về tần suất tiêu thụ thức ăn nhanh nào được thực hiện tại đây. Chúng tôi thực hiện nghiên cứu này tại trường THPT Hùng Vương nhằm tìm hiểu tần suất tiêu thu thức ăn nhanh và các yếu tố liên quan

\section{II. ĐỐI TƯỢNG VÀ PHƯƠNG PHÁP NGHIÊN CỨU}

Đối tượng nghiên cứu: học sinh đang học tại trường THPT Hùng Vương, quận 5 , thành phố Hồ Chí Minh năm 2021 đồng ý tham gia nghiên cứu. Loại những học sinh không trả lời câu hỏi về tần suất sử dụng thức ăn nhanh trong 1 tháng trở lại đây và những học sinh trả lời được ít hơn $70 \%$ bộ câu hỏi và những học sinh vắng mặt trong tất cả các buổi thu thâp dữ liệu.

Thiết kế nghiên cứu: Nghiền cứu mô tả cắt ngang.

Cỡ mẫu: Mẫu được chon bằng phương pháp chon mẫu phân tầng, sử dụng công thức tính cõ̃ mấu ước lượng một tỉ lệ:

$$
n=\frac{z_{\left(1-\frac{\alpha}{2}\right) \times P \times(1-P)}^{2}}{d^{2}}
$$

Trong đó: $\mathrm{n}$ là cõ̃ mẫu tối thiểu cho nghiên cứu; $a$ : xác suất sai lầm loại $\mathrm{I}, \mathrm{a}=0,05$ (KTC $95 \%) ; Z^{2}(1-a / 2)$ : trị số phân phối chuẩn, $Z=1,96$ (ước lượng KTC $95 \%$ với $a=0,05$ ); p: Tỉ lệ ước lượng sử dụng thức ăn nhanh. Chúng tôi thực hiện phương pháp Pilot và $p$ tính được là $44 \%$; d: sai số cho phép của ước lượng, chọn $\mathrm{d}=$ 0,05 . Thay số vào ta được $n=379$ học sinh. Dự trù mất mẫu $5 \%=>n=398$ học sinh.

Xử lý và phân tích số liệu: Sử dụng phần mềm Epidata 3.1 để nhập liệu. Xử lý và phân tích dữ kiện bằng phần mềm Excel của Office 365 và phần mềm Stata 14.3.

\section{KẾT QUẢ NGHIÊN CỨU VÀ BÀN LUẬN}

Bảng 1. Đặc điểm đối tượng nghiền cứu $(n=420)$

\begin{tabular}{|c|c|c|c|}
\hline Đặc tính & Tân số & \multicolumn{2}{|c|}{ Tỉ lệ (\%) } \\
\hline \multicolumn{4}{|c|}{ Khốí } \\
\hline 10 & 133 & \multicolumn{2}{|c|}{31,7} \\
\hline 11 & 173 & \multicolumn{2}{|c|}{41,2} \\
\hline 12 & 114 & \multicolumn{2}{|c|}{27,1} \\
\hline \multicolumn{4}{|c|}{ Giới } \\
\hline Nam & 244 & \multicolumn{2}{|c|}{58,1} \\
\hline Nữ & 176 & \multicolumn{2}{|c|}{41,9} \\
\hline \multicolumn{2}{|c|}{ Trung bình - độ lệch chuẩn } & Min & Max \\
\hline Tuối & $16,7 \pm 0,8$ & 15,2 & 18,2 \\
\hline Chiều cao $(\mathrm{cm})$ & $165,9 \pm 8,1$ & 145 & 187 \\
\hline Cân nặng (kg) & $59,5 \pm 12,3$ & 38 & 110 \\
\hline
\end{tabular}

Trong mấu nghiên cứu, học sinh lớp 11 chiếm tỉ lệ cao nhất với $41,2 \%$. Tî lệ chênh lệch giới tính khá cao $(16,2 \%)$, tuổi trung bình trong nghiên cứu là 16,7 . Cân nặng, chiêu cao trung bình tương ứng là $59,5 \mathrm{~kg}$ và $165,9 \mathrm{~cm}$. 
Bảng 2. Đặc điểm yêu tố gia đình

\begin{tabular}{|c|c|c|}
\hline Đăc tính & Tân số & Tỉ lệ (\%) \\
\hline \multicolumn{3}{|c|}{ Người sống cùng } \\
\hline Cả cha và mẹ & 350 & 83,6 \\
\hline $\begin{array}{l}\text { Cha, me hoăc người } \\
\text { thân khác }\end{array}$ & 70 & 16,4 \\
\hline \multicolumn{3}{|c|}{ Trình độ học vấn của cha } \\
\hline Dưới tiếu học & 20 & 4,8 \\
\hline Tốt nghiệp tiểu học & 28 & 6,7 \\
\hline Tốt nghiệp THCS & 72 & 17,2 \\
\hline Tốt nghiệp THPT & 121 & 29,0 \\
\hline Trền THPT & 177 & 42,3 \\
\hline \multicolumn{3}{|c|}{ Trình độ học vấn của mẹ } \\
\hline Dưới tiếu học & 17 & 4,1 \\
\hline Tốt nghiệp tiếu học & 52 & 12,4 \\
\hline Tốt nghiệp THCS & 68 & 16,2 \\
\hline Tốt nghiệp THPT & 112 & 26,7 \\
\hline Trên THPT & 170 & 40,6 \\
\hline \multicolumn{3}{|c|}{ Bữa cơm gia đình } \\
\hline < 7 lần/tuần & 83 & 19,8 \\
\hline 7 - 14 lần/tuần & 174 & 41,4 \\
\hline > 14 lần/tuần & 163 & 38,8 \\
\hline \multicolumn{3}{|c|}{ Cha sử dụng thức ăn nhanh thường xuyên } \\
\hline Không & 378 & 90,0 \\
\hline Có & 42 & 10,0 \\
\hline \multicolumn{3}{|c|}{ Mẹ sử dụng thức ăn nhanh thường xuyên } \\
\hline Không & 389 & 92,6 \\
\hline Có & 31 & 7,4 \\
\hline
\end{tabular}

Theo kết quả nghiên cứu, đa phần học sinh đang sống cùng với cả cha và me chiếm $83,6 \%$. Trình đô hơc vấn của cha, me đối tượng tham gia nghiên cứu cao nhất là trên THPT $(42,3 \%$ và $40,6 \%)$, và thấp nhất là dưới tiểu học $(4,8 \%$ và $4,1 \%)$. Số lần sử dụng bữa cơm gia đình phù hợp với đối tượng tham gia nghiên cứu nhất là 7 - 14 lần/tuần chiếm 41,4\%. Đa số học sinh tham gia nghiên cứu đều cho rằng cha và mẹ không sử dụng thức ăn nhanh thường xuyên với tỉ lệ tương ứng $90,0 \%$ và $92,6 \%$.

Bảng 3. Tình trạng dinh dướng của đối tượng nghiên cứu $(n=420)$

\begin{tabular}{|c|c|c|}
\hline Đặc tính & Tân số & Tỉ lệ (\%) \\
\hline \multicolumn{3}{|c|}{ Tình trang dinh dướng } \\
\hline Suy dinh dưỡng & 18 & 4,3 \\
\hline Bình thường & 318 & 75,7 \\
\hline Thừa cân & 66 & 15,7 \\
\hline Béo phì & 18 & 4,3 \\
\hline $\begin{array}{l}\text { Học sinh có tì } \\
\text { thường chiếm tỉ lệ } \\
\text { học sinh thừa cân c } \\
\text { Bảng 4. Tần su } \\
\text { (n= 420) }\end{array}$ & trang din & $\begin{array}{l}\text { dưỡng bình } \\
\text { ngoài ra tỉ lệ } \\
\text { úc 15,7\% ăn nhanh }\end{array}$ \\
\hline Đặc tính & Tân số & Tỉ lệ (\%) \\
\hline Không sử dung & & \\
\hline
\end{tabular}

\begin{tabular}{|c|c|c|}
\hline 1 - 3 lần/tháng & 182 & 43,3 \\
\hline 1 - 2 lần/tuần & 114 & 27,2 \\
\hline$\geq 3$ lần/tuần & 64 & 15,2 \\
\hline
\end{tabular}

Phần lớn đối tượng nghiên cứu sử dụng thức ăn nhanh 1-3 lần/tháng với tỉ lệ $43,3 \%$, chỉ có $14,3 \%$ không sử dụng thức ăn nhanh.

Bảng 5. Đăc điểm sứ dụng thức ăn nhanh $(n=360)$

\begin{tabular}{|c|c|c|}
\hline Đặc tính & Tân số & Tỉ lệ (\%) \\
\hline \multicolumn{2}{|c|}{ Loại thức ăn nhanh thường sứ dụng } \\
\hline Hamburger & 219 & 60,8 \\
\hline Pizza & 189 & 52,6 \\
\hline Gà rán & 292 & 81,1 \\
\hline Khoai tây chiên & 249 & 69,2 \\
\hline Sandwich & 167 & 46,4 \\
\hline Khác (mỳ ý,...) & 18 & 5,0 \\
\hline
\end{tabular}

Thương hiệu thức ăn nhanh thường sử dụng

\begin{tabular}{|c|c|c|}
\hline KFC & 254 & 70,6 \\
\hline Lotteria & 214 & 59,4 \\
\hline Jollibee & 117 & 32,5 \\
\hline McDonald & 159 & 44,2 \\
\hline Pizza Hut & 145 & 40,3 \\
\hline Burger King & 87 & 24,2 \\
\hline Subway & 24 & 6,7 \\
\hline Dominos Pizza & 175 & 48,6 \\
\hline Popeyes & 197 & 54,7 \\
\hline Khác (Texas, ...) & 38 & 10,6 \\
\hline
\end{tabular}

Ba loại thức ăn nhanh được sư dụng nhiều nhất là gà rán $81,1 \%$, khoai tây chiên $69,2 \%$, hamburger $60,8 \%$. Thương hiệu thức ăn nhanh được sử dụng nhiều nhất là KFC và Lotteria tương ứng với $70,6 \%$ và $59,4 \%$.

Bảng 6. Lý do sứ dụng thức ăn nhanh $(n=360)$

\begin{tabular}{|c|c|c|}
\hline Đặc tính & $\begin{array}{c}\text { Tần } \\
\text { số }\end{array}$ & $\begin{array}{c}\text { Tỉ lệ } \\
(\mathbf{\%})\end{array}$ \\
\hline Lý do sử dụng thức ăn nhanh & & \\
\hline Giá hợp lí & 175 & 48,6 \\
\hline Hương vị hấp dân & 306 & 85,0 \\
\hline Nhanh và tiện lợi & 284 & 78,9 \\
\hline Dê dàng tiếp cận & 262 & 72,8 \\
\hline Quảng cáo hấp dân & 109 & 30,3 \\
\hline $\begin{array}{c}\text { Môi trường tại cửa hàng thoải } \\
\text { mái vui vẻ }\end{array}$ & 177 & 49,2 \\
\hline $\begin{array}{c}\text { Gia đình không chuấn bị } \\
\text { bữa ăn gia định }\end{array}$ & 153 & 42,5 \\
\hline Gia đình, bạn bè thích sử dụng & 83 & 23,1 \\
\hline Giao lưu tiếp xúc với bạn bè & 99 & 27,5 \\
\hline Khuyến mãi & 210 & 58,3 \\
\hline Nhiều dinh dưỡng & 54 & 15,0 \\
\hline
\end{tabular}

Hương vị, nhanh chóng tiện lợi và dễ dàng tiếp cân là 3 lí do lựa chọn sử dụng thức ăn nhanh phổ biến nhất với tỉ lệ lần lượt là $85,0 \%$, $78,9 \%$ và $72,8 \%$. 
Bảng 7. Tân suât sử dụng thức ăn nhanh và các yêu tố liên quanĐặc tính

\begin{tabular}{|c|c|c|c|c|}
\hline & \multicolumn{2}{|c|}{ Tân suất sử dụng } & \multirow[b]{2}{*}{$\mathbf{p}$} & \multirow{2}{*}{ PR (KTC 95\%) } \\
\hline & Thường xuyên & Không thường xuyên & & \\
\hline Tuối & $16,7 \pm 0,8$ & $16,6 \pm 0,8$ & 0,157 & $0,91(0,79-1,04)$ \\
\hline \multicolumn{5}{|c|}{ Giới } \\
\hline Nam & $100(41,0)$ & $144(59,0)$ & & 1 \\
\hline Nữ & $78(44,3)$ & $98(55,7)$ & 0,494 & $1,08(0,86-1,35)$ \\
\hline \multicolumn{5}{|c|}{ Tình trạng dinh dưỡng } \\
\hline Bình thường & $137(43,1)$ & $181(56,9)$ & & 1 \\
\hline Suy dinh dưỡng & $6(33,3)$ & $12(66,7)$ & 0,45 & $0,77(0,4-1,51)$ \\
\hline Thừa cân & $28(42,4)$ & $38(57,6)$ & 0,922 & $0,98(0,72-1,34)$ \\
\hline Béo phì & $7(38,9)$ & $11(61,1)$ & 0,735 & $0,90(0,5-1,63)$ \\
\hline \multicolumn{5}{|c|}{ Bữa cơm gia đình } \\
\hline < 7 lần/tuần & $46(55,4)$ & $37(44,6)$ & & 1 \\
\hline 7 - 14 lần/tuần & $78(44,8)$ & $96(55,2)$ & 0,001 & $0,77(0,67-0,89)$ \\
\hline > 14 lần/tuần & $54(33,1)$ & $109(66,9)$ & & $0,6(0,45-0,79)$ \\
\hline \multicolumn{5}{|c|}{ Cha sử dụng thức ăn nhanh thường xuyên } \\
\hline Không & $153(40,5)$ & $225(59,5)$ & & 1 \\
\hline Có & $25(59,5)$ & $17(40,5)$ & 0,007 & $1,47(1,11-1,94)$ \\
\hline \multicolumn{5}{|c|}{ Mẹ sử dụng thức ăn nhanh thường xuyên } \\
\hline Không & $159(40,9)$ & $230(59,1)$ & & 1 \\
\hline Có & $19(61,3)$ & $12(38,7)$ & 0,009 & $1,50(1,11-2,03)$ \\
\hline
\end{tabular}

Nghiên cứu tìm thấy có liên quan có ý nghĩa thống kê giữa tần suất sử dụng thức ăn nhanh với tần suất sử dụng bữa cớm gia đình $(p<$ $0,001)$, những học sinh sử dụng bữa cơm gia đình càng thường xuyên thì tần suất sử dụng thức ăn nhanh càng giảm.

Có mối liên quan giữa tần suất sử dụng thức ăn nhanh với cha/me sử dụng thức ăn nhanh thường xuyên. Cụ thể cha sử dụng thức ăn nhanh thường xuyên thì con cái sẽ sử dụng thức ăn nhanh gấp 1,47 lần (KTC 95\%: 1,11 - 1,94), tương tự với me sử dụng thức ăn nhanh thường xuyên thì con cái sẽ sử dụng thức ăn nhanh gấp 1,5 lần (KTC 95\%: 1,11 - 2,13).

\section{BÀN LUÂNN}

Tình trang dinh dưỡng bình thường là phổ biến nhất cho các đối tượng nghiên cứu với tỉ lệ $75,7 \%$, tuy nhiên tình trạng thừa cân cũng khá cao với $15,7 \%$, tỉ lệ đối tượng tham gia nghiên cứu có tình trạng dinh dưỡng béo phì không cao chỉ $4,3 \%$. Kết quả này có sự tương đồng với nghiên cứu về dinh dưỡng cửa tác giả Nguyễn Thanh Long Sơn được thực hiện trên đối tượng học sinh THPT tại thành phố Hồ Chí Minh vào năm 2018 [2]. Giải thích cho sự tương đồng này là do sự tương đồng trong môi trường và văn hóa của của hai nghiên cứu.

Kết quả từ nghiên cứu cho thấy tỉ lệ học sinh sử dụng thức ăn nhanh ở mức độ thường xuyên ( $\geq 1$ lần/ tuần) khá cao chiếm $42,4 \%$, tuy nhiên kết quả này vấn rất thấp nếu so với kết quả từ nghiên cứu trên đối tượng thanh thiếu niên ở tỉnh Sanandaj, Iran được thực hiện bởi tác giả Foad Almoradi với 69,8\% [5]. Lý giải cho sự khác biệt này là do sự khác biệt quá lớn về văn hóa cũng như thị trường thức ăn nhanh. Mặt khác, kết quả từ nghiên cứu của chúng tôi lại khá tương đồng với kết quả từ nghiên cứu của tác giả Võ Thị Trúc Ly được thực hiện trên đối tượng học sinh THCS với tỉ lệ sử dụng thức ăn nhanh ở mức độ thường xuyên là 39,8\% [1].

Tân suất sử dụng bữa cơm gia đình, cha sử dụng thức ăn nhanh thường xuyên, me sử dụng thức ăn nhanh thường xuyên đều có mối liên quan với tần suất sử dụng thức ăn nhanh của học sinh với KTC 95\%; $p<0,05$. Những học sinh sử dụng bữa cớm gia đình $7-14$ lần/tuần sẽ sử dụng thức ăn nhanh gấp 0,77 lần so với nhóm sử dụng bữa cơm gia đình < 7 lần/tuần, nhóm sử dụng bữa cơm gia đình > 14 lần/tuần sử dụng thức ăn nhanh gấp 0,6 lần so với nhóm $<7$ lần/tuần. Những học sinh cho rằng có cha, me sử dụng thức ăn nhanh thường xuyên sẽ sử dụng thức ăn nhanh gấp 1,47 và 1,50 lần so với những học sinh còn lại. Mối liên quan này cũng được chứng minh bằng mội vài nghiên cứu khác trên thế giới. Tại Hoa Kỳ vào năm 2018 một nghiên cứu của tác giả Kathryn Walton đã cho thấy việc sử dụng bữa cớm gia đình thường xuyên sẽ làm giảm tần suất sử dụng thức ăn nhanh [8]. Vào năm 2015 tại Ấn Độ, nghiên cứu của tác giả Nitin Joseph đã chứng minh rằng cha 
mẹ sử dụng thức ăn nhanh thường xuyên sẽ làm tăng tần suất sử dụng thức ăn nhanh của con cái $8,9 \%$ so với nhóm còn lại $(p=0,024)[6]$.

\section{KẾT LUÂN}

Kết quả nghiên cứu cho thấy tần suất sử dụng thức ăn nhanh ở mức độ thường xuyên là $42,4 \%$ và xác định được một số các yếu tố liên quan đến tần suất sử dụng thức ăn nhanh của học sinh như tần suất sử dụng bữa cơm gia đình, cha sử dụng thức ăn nhanh thường xuyên, me sử dụng thức ăn nhanh thường xuyên. Vì vậy, vể phía nhà trường nên tăng cường truyền thông giáo dục dinh dưỡng tại nhà trường để xây dựng thói quen ăn uống lành mạnh và hợp lý cho học sinh. Về phía gia đình và học sinh nên chủ động tìm hiểu về tác hại của thức ăn nhanh đồng thời hạn chế sử dụng thức ăn nhanh và cùng nhau sử dụng bữa cơm gia đình thường xuyên hơn.

\section{TÀI LIÊU THAM KHẢO}

1. Võ Thị Trúc Ly (2017) Tân suất sử dụng thức ăn nhanh và các yêu tố liên quan ở học sinh trường THCS Lý Tự Trọng, Quận Gò Vấp, TP.HCM năm 2017, Khóa luận tốt nghiệp Cử nhân Y tế công cộng

2. Nguyến Thanh Long Sơn (2018) Tỉ lệ thưa cân béo phì và các yếu tố liên quan của hoc sinh trường THPT Nguyễn Văn Cừ huyện Hóc Môn thành phố Hồ Chí Minh năm 2018, Khóa luận tốt nghiệp bác sĩ y học dự phòng

3. Sở Y tế Hà Nam (2021), 13 lý do nên từ chối thức ăn nhanh, https://syt.hanam.gov.vn/ Pages/13-ly-do-nen-tu-choi-thuc-an-nhanh.aspx, Truy cập ngày 17 tháng 08 năm 2021.

4. Amare Tariku, Solomon Mekonnen Abebe (2018) "Overweight/obesity among school aged children in Bahir Dar City: cross sectional study". Italian journal of pediatrics, 44, (1), 17.

5. Foad Alimoradi, Parisa Jandaghi, Adeleh Khodabakhshi, Maryam Javadi, Seyed Amir Hossein Zehni Moghadam (2017) "Breakfast and fast food eating behavior in relation to sociodemographic differences among school adolescents in Sanandaj Province, Iran". Electronic physician, 9 , (6), 4510.

6. Nitin Joseph, Maria Nelliyanil, et al (2015) "Fast food consumption pattern and its association with overweight among high school boys in Mangalore city of southern India". Journal of clinical and diagnostic research: JCDR, 9, (5), LC13.

7. Supa Pengpid, Karl Peltzer (2017) "The prevalence of underweight, overweight/obesity and their related lifestyle factors in Indonesia, 20142015". AIMS Public Health, 4, (6), 633.

8. Kathryn Walton, Nicholas J Horton, Sheryl L Rifas-Shiman, et al. (2018) "Exploring the role of family functioning in the association between frequency of family dinners and dietary intake among adolescents and young adults". JAMA network open, 1, (7), e185217-e185217.

\section{ĐẶC ĐIỂM LÂM SÀNG VÀ CÂ̂N LÂM SÀNG CỦA BỆNH NHÂN LOẠN DƯỚNG NộI MÔ FUCHS}

Phạm Thị Duyên ${ }^{1}$, Lê Xuân Cung²,
Dương Mai Nga ${ }^{2}$, Phạm Ngọc Đông ${ }^{2}$

\section{TÓM TẮT}

Mục tiêu: Nhận xét đặc điểm lâm sàng và cận lâm sàng của bệnh nhân loạn dưỡng nội mô Fuchs. Đối tượng và phương pháp: Nghiên cứu mô tả cắt ngang trên 40 mắt của 23 bệnh nhân trong 15 gia đỉnh được chẩn đoán loạn dưỡng nội mô Fuchs từ tháng 8/2020 đến tháng 7/2021. Kết quả: Có 10 bệnh nhân nam và 13 bệnh nhân nữ. Tuổi trung bình tại thời điểm phát hiện bệnh là $58,0 \pm 14,6$ tuổi. 100\% bệnh nhân bị bệnh cả 2 mắt. Có 6 bệnh nhân được phát hiện bệnh do đi khám tình cờ hoăc khám sàng lọc, 17 bệnh nhân đi khám vì có triệu chứng cớ năng như nhìn mờ hoặc chói, cộm, chảy nước mắt từng đợt.

${ }^{1}$ Bệnh Viện Mắt Thái Bình

${ }^{2}$ Bệnh viện Mắt Trung ương

Chịu trách nhiệm chính: Pham Thị Duyên

Email: Nhocphongvu@gmail.com.

Ngày nhận bài: 16.9.2021

Ngày phản biên khoa họ: 3.11.2021

Ngày duyệt bài: 18.11.2021
Khám lâm sàng thấy 25 mắt giác mạc còn trong, 15 mắt phù giác mạc. 33 mắt có hình ảnh guttae ở mặt sau giác mac, 7 mắt không quan sát được măt sau giác mac gồm 5 mắt giác mac phù, bong biểu mô nhiều và 2 mắt giác mạc đục, sẹo xơ ở giai đoạn cuối. Số lượng tế bào nội mô trung bình của 9 mắt đếm được nội mô là $2310 \pm 515$ tế bào $/ \mathrm{mm}^{2}$. Độ dày giác mạc trung bình của 40 mắt là $593,8 \pm 67,9 \mu m$. Kết luận: Bệnh loạn dưỡng nội mô Fuchs tại Việt Nam có các đắc điểm lầm sàng và cân lâm sàng điển hình như mô tả trong y văn. Chụp tế bào nội mô và đo độ dày giác mạc là hai xét nghiệm cận lậm sàng quan trọng trong chẩn đoán và theo dõi bệnh.

Tư khóa: Loạn dưỡng nội mô Fuchs.

\section{SUMMARY}

\section{CLINICAL AND SUBCLINICAL CHARACTERISTICS OF FUCHS}

ENDOTHELIAL CORNEAL DYSTROPHY

Objectives: Evaluation of the clinical and subclinical features of Fuchs endothelial corneal dystrophy. Subjectives and Method: A cross- 